\title{
The Subacute Toxicity of 1,1-Dimethylhydrazine
}

\author{
Herbert H. Cornish and Rolf Hartung \\ Department of Industrial Health, School of Public Health, The University of Michigan, \\ Ann Arbor, Michigan 48104
}

Received July 16, 1968

\begin{abstract}
The Subacute Toxicity of 1,1-Dimethylhydrazine. CORNiSH, HerberT H., and Hartung, Rolf (1969). Toxicol. Appl. Pharmacol. 15, 62-68. Daily injections of $70,50,30$, or $10 \mathrm{mg} \mathrm{UDMH} / \mathrm{kg}$ resulted in the death of $9,6,5$, and 0 rats, respectively, in each group of 10 . All deaths occurred within the first 3 days. Animals surviving the first 3 days began to gain weight even though daily dosing was continued. Animals receiving more than 10 $\mathrm{mg} / \mathrm{kg} /$ day were markedly diuretic throughout the 21-day experimental period. Blood urea nitrogen and serum glutamic-oxaloacetic transaminase (SGOT) levels were significantly elevated in the $50 \mathrm{mg} / \mathrm{kg}$ dose group at 21 days. SGOT also appeared somewhat elevated in the $30 \mathrm{mg} / \mathrm{kg} /$ day group. Histopathologic studies showed some evidence of early lipid infiltration in the tubular epithelium of the kidney. Thus, although some animals appear to adjust to relatively high daily doses of UDMH, biochemical and histologic evidence indicates mild kidney damage in these animals.
\end{abstract}

Primarily due to the interest in unsym-dimethylhydrazine (UDMH) as a rocket fuel, considerable research has been undertaken to define the hazards that may be associated with the use of this compound (Witkin, 1956; O'Brien et al., 1964; Cornish et al., $1965)$.

Most of the data deal with the effects of a single large dose of UDMH on the experimental animal. The primary effects are tonic-clonic convulsions and death by respiratory arrest. The role of vitamin $B_{6}$ as it relates to UDMH toxicity has also been the subject of numerous studies (Reeves, 1961; Geake et al., 1966). The ability of pyridoxine to reverse the convulsive effects of UDMH demonstrates rather well the acute vitamin $\mathrm{B}_{6}$ deficiency produced by UDMH apparently through the formation of a UDMH-pyridoxal (or pyridoxal phosphate) hydrazone.

Few studies have been reported concerning the effect of repeated doses of UDMH on experimental animals. Back and Thomas (1963) reported 21-day studies on rats at a daily intraperitoneal dose of $10 \mathrm{mg} / \mathrm{kg} / \mathrm{day}$. This daily dose was apparently without effect. No subacute studies have been reported using daily doses (ip or oral) greater than $10 \mathrm{mg} / \mathrm{kg} /$ day. Rinehart et al. (1960) reported on the subacute and chronic toxicity of UDMH vapors. Animals were exposed to concentrations ranging from 50 to $140 \mathrm{ppm}, 6$ hours a day, for up to 26 weeks. Tremors, convulsions, and death occurred at high exposure levels. Dogs exposed to $5 \mathrm{ppm}$ of UDMH for 26 weeks showed slight hemolytic anemia and bilirubinemia. 
The present study was designed to measure the effect of repeated daily doses of UDMH on rats. Dosage levels ranged from 10 to $70 \mathrm{mg} / \mathrm{kg} /$ day given by ip injection.

\section{METHODS}

Female rats of the Sprague-Dawley strain were utilized in this study. Animals were given food and water ad libitum.

Groups of 10 female rats weighing approximately 225 g each were given daily ip injections of $70,50,30$, or $10 \mathrm{mg} / \mathrm{kg}$ of UDMH for a period of 3 weeks. The solution injected was a constant concentration of $25 \mathrm{mg} / \mathrm{ml}$. A fifth group received a comparable volume of $0.9 \% \mathrm{NaCl}$. The $10 \mathrm{mg} / \mathrm{kg}$ treatment group was given 18 injections; all other groups received 21 . The belly of each rat was shaved at the beginning of the study, disinfectant (Bactine) was applied before each injection, and a sterile needle was used for each rat. The injection site was alternated daily from side to side. The UDMH solution of $25 \mathrm{mg} / \mathrm{ml}$ was made up immediately before use.

Seven animals from each group were kept in individual metabolism cages for measurement of urine excretion. Water bottles were checked carefully to prevent dilution of urine samples. Daily body weight and urine excretion were recorded.

At the end of the study period, surviving rats were sacrificed, organ weights were determined, and tissue samples from 2 rats in each group were taken for histopathologic evaluation. White blood cell counts, hemoglobin, hematocrit, blood urea nitrogen, and serum glutamic-oxaloacetic transaminase (SGOT) levels were determined on all animals. One unit is equivalent to an optical density change of 0.001 .

Data are reported as the mean \pm one standard error.

\section{RESULTS}

Mortality data from this study are shown in Table 1. All animals survived a dose of $10 \mathrm{mg} / \mathrm{kg}$ of UDMH per day for a 3-week period. Half of the animals (5) survived at the $30 \mathrm{mg} / \mathrm{kg}$ dose, 4 survived the $50 \mathrm{mg} / \mathrm{kg}$ level, and 1 survived the $70 \mathrm{mg} / \mathrm{kg}$ dose. All deaths occurred within the first 3 days. After this time, all animals survived even though daily dosing continued for 3 weeks.

Body weight losses (Fig. 1) of surviving animals were also largely restricted to the first few days after the beginning of dosing and occurred in animals at all dosage levels.

TABLE 1

MoRTALITY OF RATS GIVEN DAILY INTRAPERITONEAL INJECTIONS OF UDMH

\begin{tabular}{|c|c|c|c|c|c|}
\hline \multirow[b]{2}{*}{ Day of death } & \multicolumn{4}{|c|}{ Dose (mg/kg/day) } & \multirow{2}{*}{$\begin{array}{l}\text { Saline } \\
\text { control }\end{array}$} \\
\hline & 70 & 50 & 30 & 10 & \\
\hline Day 1 & 3 & 0 & 0 & 0 & 0 \\
\hline Day 2 & 6 & 5 & 1 & 0 & 0 \\
\hline Day 3 & 0 & 1 & 4 & 0 & 0 \\
\hline Total & $9 / 10$ & $6 / 10$ & $5 / 10$ & $0 / 10$ & $0 / 10$ \\
\hline
\end{tabular}


Even the control group injected with saline exhibited a slight weight loss during the first few days. Animals receiving $10-30 \mathrm{mg} / \mathrm{kg} /$ day of UDMH resumed their normal growth pattern rather promptly, while those receiving $50 \mathrm{mg} / \mathrm{kg} / \mathrm{day}$, although continuing to gain weight, had a more erratic course and remained considerably below the average weight of the other groups for several weeks. The 1 surviving rat receiving $70 \mathrm{mg} / \mathrm{kg} /$ day gained weight slowly and was still bclow its original weight at time of sacrifice.

The average daily urine output of the group of rats given $10 \mathrm{mg} / \mathrm{kg} /$ day was the same as the control group (Fig. 2). Daily injections of $30-50 \mathrm{mg} / \mathrm{kg} /$ day resulted in marked and sustained diuresis throughout the 3-week period. Total urine output for this period is included in Table 2, the volume in the two high-dose groups being more than double that of control animals.

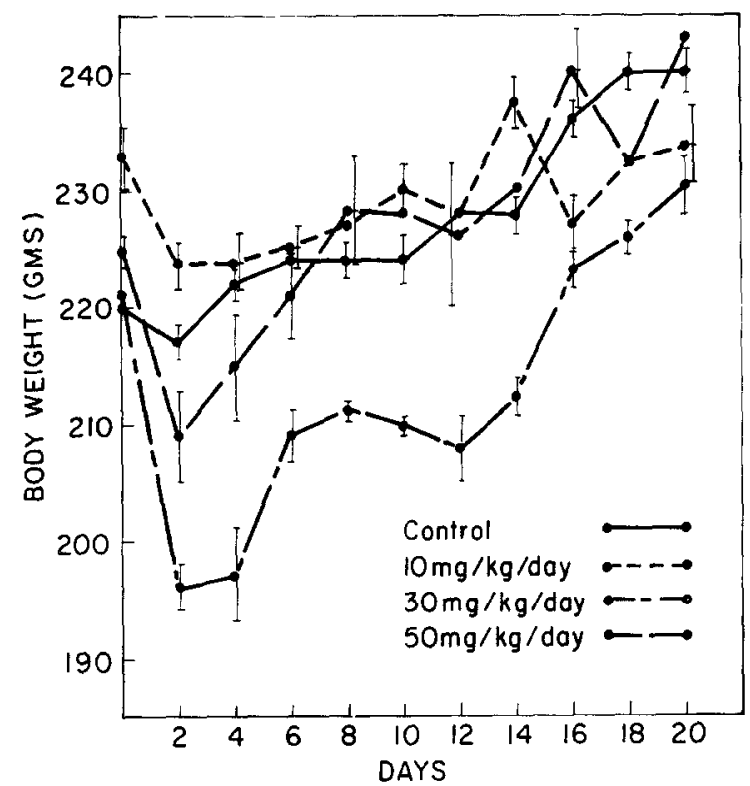

FIG. 1. Growth rates of rats receiving daily intraperitoneal injections of UDMH, mean \pm 1 standard error.

A summary of the data obtained in a number of other studies conducted on these animals at the termination of the injection schedule is shown in Table 2. Mean white blood cell counts, hemoglobin, and hematocrit values were not affected by the 10,30, and $50 \mathrm{mg} / \mathrm{kg}$ daily dose of UDMH over the 3-week period. The single rat surviving the $70 \mathrm{mg} / \mathrm{kg}$ daily dose was apparently near death and had a white cell count of only 1800. Three of the 4 surviving rats given $50 \mathrm{mg} / \mathrm{kg} /$ day had elevated blood urea nitrogen levels suggestive of early kidney damage.

SGOT levels showed an increasing elevation with increasing dosage levels. The single surviving member of the group receiving $70 \mathrm{mg} / \mathrm{kg} /$ day had an SGOT level of 124 units compared with control levels averaging $47.2 \pm 2.0$ units.

Organ to body weight ratios expressed as percent of body weight, for heart, liver, kidney, spleen, and lung of these animals are shown in Table 3. None of these values are significantly different from the control groups. 
Histopathologic findings in these animals were slight. In the one surviving animal receiving $70 \mathrm{mg} / \mathrm{kg} /$ day, the liver showed slight lipid infiltration, but similar findings were present in a number of control animals. The kidney, however, showed swelling of the tubular epithelial cells, and multiple fat droplets, with large droplets in the renal tubules and an occasional small droplet in a glomerular capillary. Some of the $50 \mathrm{mg} / \mathrm{kg} /$ day group also showed early fatty changes in the tubular epithelium of the kidney which were not seen in the control group.

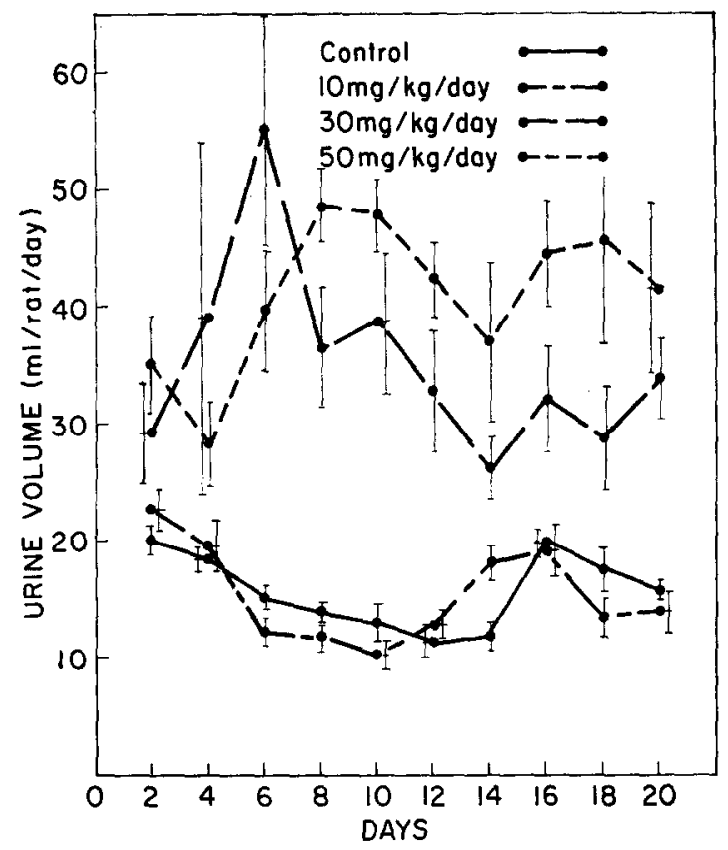

FIG. 2. Daily urine volumes of rats receiving daily intraperitoneal injections of UDMH, mean \pm 1 standard error.

\section{DISCUSSION}

Repeated injections of 70,50 , or $30 \mathrm{mg} / \mathrm{kg} /$ day of UDMH resulted in a high rat mortality rate. On the $70 \mathrm{mg} / \mathrm{kg} /$ day dose, 9 of 10 rats died during the first 2 days. On the $50 \mathrm{mg} / \mathrm{kg} /$ day level, 6 rats died during days 2 and 3. On the $30 \mathrm{mg} / \mathrm{kg} /$ day dose, 5 of 10 rats died during days 2 and 3 . Four of these deaths occurred on day 3. Deaths occurring on the second and third day of dosing suggest that there is accumulative or delayed effect of UDMH. However, all animals that survived the first 3 days of dosing survived for the total 3-week period. Animals on the $10 \mathrm{mg} / \mathrm{kg}$ per day dose and the saline controls all survived the 21 -day treatment period. The essentially no effect level of $10 \mathrm{mg} / \mathrm{kg}$ day is consistent with the studies of Back and Thomas (1963), who found no effect after 20 days of ip injections at this level. Animals surviving the initial doses all gained weight at approximately the same rate. The initial weight loss in these animals was proportional to the dose of UDMH, being greatest at the high levels. At the end of the 3-week period, the animals on the 10 and $30 \mathrm{mg} / \mathrm{kg} /$ day doses had body 
weights comparable to the controls. Animals receiving $50 \mathrm{mg} / \mathrm{kg} /$ day were approximately $10 \mathrm{~g}$ below the weight of control rats at the end of 3 weeks.

There is little evidence of an effect on the hematopoietic system since white blood cell count, hemoglobin, and hematocrit values of all animals in the 10, 30, and 50 $\mathrm{mg} / \mathrm{kg} /$ day groups were comparable to controls, although white counts became more variable with increasing dosage. The white cell count in the single surviving animal in the $70 \mathrm{mg} / \mathrm{kg} /$ day group was markedly depressed and the animal near death. This is somewhat in contrast to the report of Rinehart et al. (1960), who found definite anemia in dogs exposed to UDMH. They also noted, however, that dogs were significantly more sensitive to UDMH than were rats. In addition, the vapor exposure studies on dogs were continued for $13-26$ weeks. It is also interesting to note that sustained diuresis in these animals did not result in hemoconcentration.

Earlier studies have shown that a single dose of UDMH produced a rather marked diuresis in rats (Barth et al., 1967). Not only was an immediate diuresis noted in the present study with doses of $30 \mathrm{mg} / \mathrm{kg}$, or greater, but diuresis continued over the entire 3-week period of injection. Total urine output over this period was more than twice that of normal rats. Thus, there was no readjustment of excretion rate when UDMH was injected on a daily basis over a 21-day period. It is difficult to determine whether the diuretic effect was dose dependent, although after the first week, the urine output of the $50 \mathrm{mg} / \mathrm{kg} /$ day dose group remained consistently above that of the $30 \mathrm{mg} / \mathrm{kg} /$ day group for the remaining 2 weeks. Although the mechanism of this diuretic action is not clear, previous studies have shown that this is primarily a water diuresis (Barth et al., 1967).

The elevation of blood urea nitrogen levels in animals on the high dose is suggestive of early kidney damage. Tissue pathologic changes would tend to support this finding since there was cloudy swelling and lipid infiltration in the renal tubules in the $\mathbf{5 0}$ and $70 \mathrm{mg} / \mathrm{kg} /$ day groups.

The elevation of SGOT is more difficult to interpret. What appears to be a gradual increase in SGOT in the various groups is not due to diuresis and hemoconcentration, since hematocrit values remain constant in all groups. Whether this is an indication of early liver or kidney damage is not apparent. Although the livers of some treated animals showed early degenerative fatty infiltration, similar findings occur in some control animals. The report by Reinhardt and Dinman (1965) demonstrated an elevated level of rat serum lactic dehydrogenase 16 hours after a single ip injection of $80 \mathrm{mg}$ of UDMH per kilogram of body weight. No histologic evidence of liver damage was found in those studies. The SGOT increase found in the present studies is not great and could conceivably be related to the incipicnt kidney damage which is found in the histopathologic studies of the high-dose groups. That mean SGOT levels start to rise, even in the lower dosage groups, is suggestive of an early tissue effect which may not be evident in histopathologic studies.

\section{ACKNOWLEDGMENT}

This study was sponsored by the Commission on Environmental Hygiene of the Armed Forces Epidemiological Board and was supported, in part, by the U.S. Army Medical Research and Development Command, under Contract No. DA-49-193-MD-2322. 
The technical assistance of Dr. Walter E. Brewer, Thomas Hill, and Dr. Thomas Markham is gratefully acknowledged.

\section{REFERENCES}

Back, K., and Thomas, A. (1963). Pharmacology and toxicology of 1,1-dimethylhydrazine. Am. Ind. Hyg. Assoc. J. 24, 23-27.

Barth, M., Geake, C., and CoRnish, H. (1967). 1,1-Dimethyl-hydrazine-induced diuresis. Toxicol. Appl. Pharmacol. 11, 26-34.

CoRnISH, H., GEAKE, C., and BARTH, M. (1965). Biological action of 1,1-dimethylhydrazine. Biochem. Pharmacol. 14, 1901-1904.

Geake, C., Barth, M., and Cornish, H. (1966). Vitamin $B_{6}$ and the toxicity of 1,1-dimethylhydrazine. Biochem. Pharmacol. 15, 1614-1618.

O'Brien, R., KirkPatrick, M., and Miller, P. S. (1964). Poisoning of the rat by hydrazine and alkylhydrazines. Toxicol. Appl. Pharmacol. 6, 371-377.

REEVES, J. (1961). Influence of large doses of pyridoxine hydrochloride on the convulsigenic activity of UDMH in monkeys. Report 62-31, School of Aerospace Medicine, USAF Aerospace Medical Center, Brooks Air Force Base, Texas.

ReINHARDT, C., and DinMaN, B. (1965). Toxicity of hydrazine and 1,1-dimethylhydrazine (UDMH). Arch. Environ. Health 10, 859-869.

RineharT, W., DonATI, E., and Greene, E. (1960). The subacute and chronic toxicity of 1,1-dimethylhydrazine vapor. Am. Ind. Hyg. Assoc. J. 21, 207-210.

WitkIN, L. B. (1956). Acutc toxicity of hydrazine and some of its methylated derivatives. A.M.A. Arch. Ind. Health 13, 34-36. 